\title{
Freedom of Information, Right to Access Information, Open Data: Who is at the table?
}

Professor Elizabeth Shepherd

University College London, Department of Information Studies

Gower Street, London WC1E 6BT, UK

02076792945

e.shepherd@ucl.ac.uk

\section{Abstract}

Many national governments have adopted the idea of the 'right to access information' (RTI) or 'freedom of information' (FOI) as an essential element of the rights of citizens to freedom of opinion and expression, human rights, trust in public discourse and transparent, accountable and open government. Over 100 countries worldwide have introduced access to information legislation: 50+ in Europe; a dozen in Africa; 20 in the Americas and Caribbean; more than 15 in Asia and the Pacific; two in Middle East (Banisar, 2014).

This article will provide an overview of access to information legislation, then focus on the UK Freedom of Information Act 2000 as a case example. It will report on the impact of the UK FOI Act on public authorities, with a focus on records management implications, drawing on research undertaken by University College London. In the final section, it will reflect on relationships between access to information and open government data. If governments are moving to more openness, what implications might this have for those charged with implementing FOI and RTI policies, including for records professionals?

Keywords: freedom of information, access to government information, right to information, records management, open government, open data 


\section{Freedom of Information, Right to Access Information, Open Data: who is at the table?}

\section{Introduction}

Many national governments have adopted the idea of the 'right to access information' (RTI) or 'freedom of information' (FOI) as an essential element of the rights of citizens to freedom of opinion and expression, human rights, trust in public discourse and transparent, accountable and open government. As far back as 1948 the United Nations Universal Declaration of Human Rights linked freedom of expression and the right 'to seek, receive and impart information.' In 1966, the International Covenant on Civil and Political Rights stated that '...access to information is inextricably tied to freedom of expression.' By 2006, 70 countries had access to information legislation and a further 50 had made some moves towards this (Banisar, 2006). Now, over 100 countries worldwide have introduced legislation: 50+ in Europe; a dozen in Africa; 20 in the Americas and Caribbean; more than 15 in Asia and the Pacific; two in Middle East (Banisar, 2014).

This article will provide an overview of access to information legislation, then focus on the UK Freedom of Information Act (FOIA) 2000 as a case example. It will report on the impact of the Act on public authorities, with a focus on records management implications, drawing on research undertaken by University College London (UCL). Although the UK's experience of FOI has not been especially influential within the Commonwealth, the underlying historic recordkeeping systems are widely reflected across the Commonwealth and part of the colonial legacy, raising questions around the attitudes and assumptions of citizens towards access and openness. In the final section, it will reflect on relationships between access to information and open government data. If governments are moving to more openness, what implications might this have for those charged with implementing FOI and RTI policies, including for records professionals? ${ }^{1}$ 
The origins of freedom of information are generally dated back to the Swedish Freedom of Press Act, 1766 , but there has been rapid expansion in last 20 years, with over half of all such laws being adopted in the $21^{\text {st }}$ century. In some countries rights of access to information (RTI) are enshrined in the constitution or Bill of Rights. Many countries drafted, discussed or passed FOI laws in the 2000s, but some of those have not yet fully enacted the legislation (such as in Kenya, Botswana, Ghana). The UK was a late adopter, part of a 'Third wave' of FOI in 2000 (along with Ireland 1997, South Africa 2000, and much of Eastern Europe). The 'Second wave' included Canada (1983), Australia (1982), New Zealand (1982) in 1980s, and the 'First wave' began with the USA in 1966. By 2014, over 100 countries had such legislation and the number is still growing (Banisar, 2014). Often RTI or FOI is part of a complex set of laws regulating information access and adopted for a variety of reasons. RTI is rarely established by a single piece of comprehensive legislation: often it interacts with, contradicts or is complemented by other legislation concerning privacy, data protection, human rights, health and safety, and the environment. It is not 'one size fits all' and has some very different characteristics in different cultural contexts and legal jurisdictions.

What are the arguments in favour of such legislation? Why have so many countries gone down this road? Sometimes it has been part of a cultural and societal shift from a more secretive closed society where access to records is restricted and controlled, to a more open one in which access is seen as a civic right. FOI is often the ambition of long-running campaigns by the media and by civil society interest groups such as that led by Maurice Frankel, Director of the Campaign for Freedom of Information in the UK (CFOI, 2015). FOI is sometimes linked to modernising government, new public management and improving the processes of government. In developing countries FOI can sometimes be seen as a constitutional right in new democracies or as part of public sector reform required by funding bodies (the World Bank, IMF, or those associated with the Commonwealth). FOI is also considered as a strategy for deepening democracy and increasingly governmental accountability to its citizens, and reducing corruption, by reducing information asymmetries in society. Many politicians have asserted that FOI contributes to openness and transparency of 
government. There is a relationship between these ideas: access to information or FOI establishes a right for individuals to seek information held by public authorities, in a manner defined by law, and generally subject to exemptions for things such as national security, defence, international relations, police investigations and privacy. Transparency is a wider concept which includes making public affairs open to public scrutiny so as to enable citizens to understand the actions of their governments. FOI is a necessary part of transparency, given that such scrutiny cannot easily be conducted without access to the official records of policy-making and its execution. Openness is similar to transparency, but 'goes beyond access to documents to cover such items as opening up of processes and meetings of public bodies...concentrating on processes that allow us to see the operations and activities of government at work' (Birkinshaw, 2010, p. 29).

Although FOI establishes a statutory right to access information, it does not in itself guarantee free and unlimited information access. The legislative rights and the mechanisms by which these rights are implemented by government may differ. In some countries legislation may be enacted but never used, or written so as to prevent access, for instance through excessive exemptions. FOI may be contradicted by other pieces of legislation and in cases of threats to national security, suspended, weakened or overruled. Government and organisational culture may obstruct access: culture change in government is often needed to ensure sufficient awareness of the legislation and regulations by public officials. Advocacy is needed as well to ensure that citizens understand how to exercise their new rights. In some jurisdictions, access is effectively restricted by excessive delays, for example if there is no statutory time limit for responses. Charging fees tends to discourage requests: when application fees were introduced in Ireland in 2003, FOI requests halved from around 8000 a year to around 4000, and fees were eventually abolished (Rosenbaum, 2012). It has been suggested that 'the magnitude of FOI charges is probably the most important factor in determining the level of usage of the legislation' (McDonagh, 2006). Birkinshaw (2010, p. 30) also points out that information is not neutral: its 'control, use and regulation' are exercises in power. There are many examples of information asymmetry between governments and their citizens, recently in cases surrounding 
official inquiries into disasters, such as the Hillsborough Stadium Disaster when 96 people died in a crush at a football match and the police attempted to conceal what had happened (Hillsborough Independent Panel, 2012) and investigations into historic abuse in institutional settings, such as Australia's 'Stolen Generations' - indigenous children taken from their families and placed in institutions and foster homes (Stolen Generations, 2015). Information may be made deliberately inaccessible or inadvertently hard to find due to poor record-keeping, resulting in incomplete and unreliable records being created, or the inability of an authority to find information when it is needed.

There has been debate over the chilling effect of FOI on record creation which is said to encourage public officers to make decisions without making an official record, by oral agreements and the use of non-official channels of communication. Does FOI leave behind 'empty archives'? Some contemporary historians, rather than relying on official records, prefer to interview participants to find out what was done or said and why (Flinn and Jones, 2009). UCL Constitution Unit's research suggested little evidence of the chill on 'frank advice and deliberation' or on the quality of UK government records (Worthy, 2010). Government may create poorer official written records, but this may be linked not to FOI but rather to a general change in structures of policy-making, described in the Butler Review (2004) as 'the informality and circumscribed character of the government's procedures', dubbed by the press 'sofa government' (Guardian, 2004). The arguments put forward by ministers in the Department for Education that emails on official business sent from private email accounts were not public records illustrates this change. Are fewer records being captured and preserved because of the failure to manage digital records systems, for instance, or as a result of FOI? Constitution Unit research concluded that 'the myth was pervasive', but that in reality public officials were 'more fearful of the consequences of not having a record rather than of a record being released' (Worthy, 2010). 
FOI has limited effects on the private sector, since it generally only applies to government or public institutions (unlike data protection or privacy laws which tend to apply to all personal data regardless of where or by whom it is held). Yet, at least in the UK, private companies are increasingly responsible for public services, many of which are now delivered by either public-private partnerships or wholly by private contractors. Usually only the contracting public authority, not the private company delivering the service, is fully subject to FOI. Businesses using a law such as FOI which is free at the point of access (ie without costs to requestors) to obtain information of which they then make commercial use can be controversial. UK government rhetoric has now shifted in favour of free access to government data for commercial exploitation, asserting that this will boost the economy and be a general benefit, rather than seeking to recover access costs from business. There is a contradiction between data privacy rights and access rights which is often resolved by making personal information requests fall under data protection or privacy legislation rather than FOI. Privacy legislation gives data subjects (usually limited) rights over the processing of personal data and regulates the creation, processing and retention of personal data and records. There are significant national and cultural differences over privacy and protection of personal data. In the UK, the Data Protection Act 1998 sets out eight data protection principles, including fair and lawful processing of personal data for a specified and lawful purpose, data controllers having to be registered and protections for the rights of data subjects. These principles raise some ethical dilemmas for record-keepers: for example, access to data about third persons for research, or the accessibility and use of records in cases of regime change and human rights abuses. These are not easy to resolve.

Once FOI legislation has been enacted, there are still a number of operational requirements to make it usable. These differ in detail from jurisdiction to jurisdiction. The UK had a four and a half year implementation period to allow authorities to prepare, including developing a new, more open, organisational culture which needs to be explicitly led by senior management and chief officers, 
training staff (eg in FOI awareness to ensure that FOI requests are recognised and in the operation of new processes), setting up FOI request processes, developing publication schemes, ensuring access to legal advice in order to determine whether exemptions apply, and getting records management systems in good order. In some cases this meant the implementation of record retention and destruction schedules for first time, in line with record-keeping standards.

UCL Constitution Unit's research identified 'Laws' and 'Paradoxes' of FOI in the UK, which highlight key points (Hazell and Worthy, 2009). First, the Laws. The media has a key influence on the impact of FOI. Journalists are major users of FOI, and media reports shape public perception. Once enacted, FOI cannot be repealed, however much some politicians might dislike it Government still controls the system since it holds the information and can resist disclosure. Politicians and officials can seek to introduce delays in releasing information, although appeals systems and sanctions discourage this. Government will always be seen as secretive, however open the regime and wherever government draws the line between secrecy and openness, since citizens and the media will tend to assume secrecy and cover-up. FOI never becomes 'routine', as case law builds up and alters the landscape. A few high profile FOI requests cause disproportionate impact, and draw media attention, public controversy and political fall out. FOI does not increase public trust since the media report negatively, public trust is historically low, and FOI does not seem to change this much.

Secondly, the Paradoxes. FOI only works if almost noone uses it (there are low rates of use in the UK, less than one request in one thousand citizens: but if the number doubled to two people in a 1000, the bureaucratic system would be unable to cope). Public officials and requestors in general support the principle of FOI but deplore the practices, since the system is bureaucratic and legalistic. FOI is not much used by 'ordinary citizens', but a tiny minority, mostly activists and professionals. Bureaucracy, not secrecy, inhibits government response, since most failures to disclose are because of poor processes, failing to find the right information, having to check for exemptions and so forth. Many people think if more was published proactively, we would not need FOI, but it is very difficult 
to anticipate what requestors want, especially as many are pursuing specific private interests not shared by others.

UK Freedom of Information Act (FOIA) 2000

The second part of this article will look at the case of the UK Freedom of Information Act 2000, which was gradually implemented in different parts of the public sector, coming fully into force in January 2005. Many parts of the public sector (including local and national government and the National Health Service) were previously subject to non-statutory codes on information disclosure, but the FOIA was more comprehensive and provided statutory rights to recorded information held across the whole public sector. It imposes significant duties and responsibilities on public authorities to give access to information, seeking to make them more transparent and accountable to the public. Authorities have to release requested information, unless they can justify withholding it because an exemption in the Act applies. There are 24 exemptions, some absolute (eg national security) and the majority qualified (ie subject to an assessment of the public interest). Authorities need to know what information they hold, to manage and retrieve information effectively, deal with FOI requests within 20 working days, and disseminate information proactively through a publication scheme.

The Act covers all public authorities across England, Wales and Northern Ireland: there is a separate Act for Scotland. Its provisions apply equally, regardless of size or nature, to over 100,000 public authorities, from the national Ministries to local government, the police, the armed forces, the National Health Service, individual doctors, schools and universities, as well as the national museums. The Royal Family, Security and Intelligence Services and the Church of England are excluded, along with some nationalised industries. It does apply to the UK Parliament, although there have been periodic attempts to get Parliament excluded.

Whilst the Act covers public authorities, it does have implications for the private sector, since information received from the private sector, for example from contractors, will be 'held' by the 
authority and therefore be subject to the Act. In addition, the Secretary of State has the power to designate as a public authority one carrying out functions of a public nature. The private sector may receive FOI enquiries concerning its business with public sector.

The relationship between FOIA and the practice of corporate records management was recognised by Parliament in a Code of Practice on Records Management under Section 46 of FOIA (first published in 2002, revised in 2009) (UK MoJ, 2009). Good records management practice is promoted by The UK National Archives (TNA) and by the Information Commissioner's Office (ICO), which have responsibility to promote the observance of the Code: they signed a memorandum of understanding in 2004, renewed in 2012 (UK TNA and ICO, 2012). The Code states that, 'Freedom of information legislation is only as good as the quality of the records and other information to which it provides access. Such rights are of little use if reliable records are not created in the first place, if they cannot be found when needed or if the arrangements for their eventual destruction or transfer to an archives service are inadequate.'

Good records management is fundamental. The Act covers 'information' regardless of how it is recorded (e-mail, post-it note, tape or a formal file or register). The UK Act is fully retrospective and is not limited to information created after 2000. FOl gives a right to information not to the record itself. You do not have to be a UK citizen or live in the UK to make a request. Applicants do not have to give reasons for their requests or identify themselves beyond a contact address. Within 20 working days of receiving the written request the authority must either release the information requested, or explain its grounds for withholding it, for instance if it considers an exemption applies. The requestor has the right to be informed whether information requested is held ('duty to confirm or deny'). Public authorities have to justify withholding information and applicants have rights of appeal.

In the main, $\mathrm{FOI}$ is a responsive mode of release of information: the requestor has to make a request for information. Requests must be in writing, although they can be transmitted electronically. 
Applicants do not need to say they are making an FOI request so all officers must recognise and pass on requests as soon as they are received. Applicants can say whether they want a copy of the information, to inspect relevant records, or a summary. It is a criminal offence under the Act to alter records containing requested information, with the intent to prevent disclosure. This underlines the importance of good records management and clear records retention policies.

One aspect of FOIA is proactive, and that is the requirement for authorities to issue Publication Schemes. They must use such schemes to proactively publish some information held by the authority, including who they are and what they do; what they spend; what their priorities are; how they make decisions; policies and procedures; and their services. Publication schemes were often poorly maintained or little used, but with support from ICO they are becoming more effective. Publication schemes have good intent, but in fact, Google-type searches of websites may be more useful.

Making an effective request is not easy when you are unfamiliar with the authority's internal structures and processes. Advice compiled by the Constitution Unit (Bourke, Worthy and Hazell, 2012) and by the Information Commissioner's Office (UK ICO, 2015a) advises specificity, since a broad request can be refused; describing in detail what information is needed; asking for help from the FOI Officer; asking to see the corporate file structure first and then for specific files; trying again if your first request does not work the way you want. Requestors who refine their request, stagger a series of requests, split them up into batches, and do not expect the FOI officer to do their research for them, are more likely to succeed. Journalists use FOI very effectively because they are persistent and usually specific.

Public authorities are able to charge for dealing with requests in some circumstances, including for photocopying and postage, although fees up to a cost ceiling are not chargeable ( $f 600$ for central government and $£ 450$ for all other public authorities), but most authorities do not charge for answering a request. Some aspects are not chargeable, such as the time taken to determine whether 
or not exemptions apply. Charging for finding information due to poor records management is not acceptable. There is new provision for charging in relation to the re-use of datasets in the Protection of Freedoms Act 2012 (UK Ministry of Justice, 2013).

The most common reason for refusing to provide some or all of the information requested is that an exemption applies. There are 24 in total, although some are multi-part. There are two types:

absolute or qualified. Absolute exemptions include FOIA s.21 (information available by other means); s.23 (information relating to security bodies); s.32 (court records); s.34 (parliamentary privilege); s.36 (prejudice to affect conduct of public affairs); s.37 (communications with the Queen or her heir); s.40 (personal information: disclosures to be considered in relation to the Data Protection Act); s.41 (confidentiality); s.44 (disclosures prohibited by law). Many of these are non-controversial: information about national security bodies, court records, and where disclosure would involve breach of other legislation. Some are more contentious: should the Royal Family be absolutely exempt, and what about parliamentary privilege? The release of correspondence from the heir to the throne to government ministries was subject to significant public debate (Guardian, 2015, BBC News, 2015).

Qualified exemptions are subject to a public interest test, ie is there a public interest in disclosure that overrides the exemption? If there is a balance, then disclosure prevails. Qualified exemptions include FOIA s.22 (information intended for future publication); s.26 (defence); s.27 (international relations); s.28 (relations within UK); s.29 (economy), s.30 (investigations); s.31 (law enforcement); s.33 (audit functions); s.35 (formulation of policy); s.38 (health and safety); s.39 (environmental information); s42 (legal professional privilege); s.43 (commercial interests). However, the Secretary of State can issue a veto overriding disclosure. This is rare and generally controversial, but has been used to prevent disclosure of Cabinet committee records (UK ICO, 2012a).

If the authority refuses to disclose information, the requester can ask for an internal review. Where matters cannot be resolved through the internal complaints procedure, complaints may be made to 
the Information Commissioner's Office (UK ICO, 2015b). The ICO is the UK's independent authority charged with upholding information rights in the public interest, promoting openness by public bodies and data privacy for individuals. He or she is responsible for monitoring compliance with the Data Protection Act 1998, Privacy and Electronic Communications Regulations 2003, access to information under Freedom of Information Act 2000 and Environmental Information Regulations 2004. ICO provides training and information to organisations, conducts assessments to check organisational compliance, issues undertakings and decision notices, serves enforcement notices, and can issue civil monetary penalties up to $£ 500,000$ for data breaches and start criminal proceedings for contempt or alteration of requested information. There is a right to appeal decisions to the independent First Tier (Information Rights) Tribunal and further appeal on complex or important points can go to the Upper Tribunal, Court of Appeal or Supreme Court.

\section{The impact of FOIA in Local Government}

What difference has all this made? Research by UCL's Constitution Unit suggests that there is evidence that FOI has indeed increased transparency in national government with a greater openness of culture and decision-making taken 'in public' (Worthy, 2010). However, in local government, a study suggested that 'different bodies have very different attitudes', although overall, FOI has increased the amount of information released (Worthy et al, 2011). FOI is one of a number of factors (alongside assessments, targets, and media questions) which contributed to increased local accountability of elected representatives and the public sphere. Whether FOI has produced better decision-making processes in public authorities or better understanding by the public is debatable, and in general, requesters are not interested in this side of things. Requestors are more interested in the outcome of the decisions on a specific issue such as local education or library services. It seems that FOI 'has not had a dramatic effect on local participation, though it has enabled those already involved' to find out more. In the UK, less than $0.1 \%$ of citizens make FOI requests. FOI has had a varied impact on trust and confidence in government and other public 
authorities: some respondents in the Constitution Unit's research thought that public trust had decreased, for example after negative media reports of officials' expenses scandals, wasted funds and excessive senior salaries. Other respondents thought that trust was low and would always be so, FOI or not; while a few others believed that over the long term, trust would increase as authorities were shown to be responsive and consultative.

UCL Department of Information Studies (DIS) carried out some research on the impact of FOIA on records management in local government (funded by the Arts and Humanities Research Council, 2008-09, Shepherd, Flinn and Stevenson, 2009, 2010, 2011a, 2011b). The research focused on how well records management services prepared for and coped with the first few years of FOI implementation; what contribution records management services made to the ability of public authorities to comply with the FOI Act; how the user experience of FOI was affected by the management of records; and what the implications of FOI were for good practice in records management. $^{2}$

Records management staffing, policies and systems in the different local authorities studied were uneven with little or no standardisation of practice, although FOI encouraged authorities to make improvements. Good control over paper files was often not replicated in digital environments and collaboration with ICT departments on digital records management was variable. The quality of responses (the time taken to respond but also the completeness, relevance and reliability of the information provided) was hindered by a lack of records management good practice.

Barriers to access especially from the requestor's perspective emerged. There was often a mismatch between the council's records structures and requestor's knowledge of them. Authorities are obliged to provide assistance to the requestor to help frame the request, but they varied in their responsiveness and requestors found it difficult to 'get the questions right'. Often there was a lack of dialogue between council and requestor or a lack of knowledge within the council of their own records. 
The research also looked at the changing nature of the record under FOI. Some respondents said there were no changes to record-creating practices, while others believed that staff were generally more careful and more concise about what they wrote and that senior management was not writing things down for fear of disclosure. More positively, FOI requests highlight data which might be made priorities for proactive capture and release.

\section{A more open future}

The final part of this article looks at the recent moves towards proactive release of open government data, 'the 21st century's new raw material', to enhance public service delivery and government performance. ${ }^{3}$ According to the UK government Open Data White Paper, open data is 'accessible ... in a digital machine readable format for interoperation with other data and free of restriction on use or redistribution in its licensing conditions' (UK Cabinet Office, 2012). It is 'non-privacy-restricted and non-confidential data which is produced with public money and is made available without any restrictions on its usage or distribution'. Data should be open to all for re-use, mash-up and republication without restriction, 'based on an assumption that information should be in the public domain unless there is a good reason not to - not the other way around' (Ordnance Survey Open Data, 2010).

As Halonen states, 'the open-data movement did not originate in a vacuum' (Halonen, 2012). It has its roots in access to information and is related both to the accountability and transparency culture of FOI and to the Public Sector Information European Directive which focuses on providing information that can be easily reused for economic growth. This line of argument asserts that the public sector is an 'important data user and a source of data that can generate benefits across the economy. ..., governments could reduce their administrative costs. ... . the additional benefits that would arise from greater access to and more effective use of public-sector information... could amount to $€ 40$ billion a year in the EU' (EU, 2013). Politicians argue that open data 'would benefit the UK economy by creating jobs and stimulating innovation and at the same time increase 
transparency and accountability..., empower the citizens' public participation' and improve public services (UK Cabinet Office, 2013).

In January 2010 the UK government launched <data.gov.uk >, a web portal that provides a single access point to datasets held by public bodies, which are freely available for use. A Public Sector Transparency Board was established to 'drive forward the government's transparency agenda, making it a core part of all government business and ensuring that all Whitehall departments meet the new deadlines set for releasing key public datasets' (UK Transparency Board, 2010). UK Government published a set of fourteen principles for open government data (UK Government Open Data, 2013). These include 'public data policy and practice will be driven by the public and businesses who want to use the data'; 'public data will be published in reusable, machine-readable form'; released under open licence that enables free re-use, including commercial re-use; public data will be published using open standards; data from different departments about the same subject will be published in the same standard formats and with the same definitions, and departments will publish metadata about their datasets; data will be released as quickly as possible after collection and in as much detail as possible ('timely and fine grained'); and public bodies should actively encourage the re-use of their data.

However, some major issues have emerged during the last few years. One of the most common open data myths is that open data is achieved by simply publishing public data. In fact, data release usually necessitates additional work to provide reusable data and to avoid data redundancy and inconsistency, and problems with data integrity and quality, and with lack of interoperability. Interconnectedness through linked data raises privacy concerns. Integrating data from different datasets may compromise anonymity. The ICO issued a Code of Practice on Anonymisation in 2012 and the European Commission published new proposals about the protection of personal data which are under discussion (UK ICO, 2012b). Perhaps the reduction and management of risk of data breaches rather than their elimination is the best that can be expected. 
Use and reuse concern data producers who may be reluctant to release data; in scientific research, for instance, there is a fear that original ideas and research will be stolen or misunderstood with risk to personal reputation or public health. Some researchers think that open data can be misleading or open to political manipulation if it cannot be traced to reliable record sources (paper and digital). Access to open data is not equal and may in fact deepen the 'digital divide' as its effective use requires digital infrastructure, hardware and software, financial or educational resources and skills (Gurstein, 2010). Opening up government data implies putting everybody in a position where they can actually make use of the data. The records manager can play a major part when it comes to dealing with open data by ensuring that data released are accessible, useful, authentic and contextualised through good metadata and interoperable systems. Open data could be a huge opportunity for records managers to create new partnerships with system designers and data creators.

\section{Conclusion}

This article has given an overview of access to information and open government data issues, with a focus on the UK. The UK legacy of recordkeeping systems within the Commonwealth affects the implementation of FOI but otherwise the UK legislation, coming in the third wave globally in the early 2000s, has perhaps not been especially influential in the Commonwealth. However, as some governments move to more openness and proactive release, there are implications for a number of communities of practice, including for records professionals, who should be at the table charged with implementing FOI and RTI policies.

\section{References}

BANISAR, D. (2006) Freedom of Information around the World 2006: A Global Survey of Access to Government Information Laws, London, Privacy International. 
BANISAR, D. (2014) National Right to Information Laws, Regulations and Bills 2014 Map. http://dx.doi.org/10.2139/ssrn.1857498

BBC NEWS (2015). 'Supreme Court due to rule on Prince Charles letters' 26 March 2015. http://www.bbc.co.uk/news/uk-32061819

BIRKINSHAW, P. (2010) Freedom of Information. The Law, the Practice, and the Ideal, Cambridge, CUP.

BUTLER REVIEW (2004). Review of Intelligence on Weapons of Mass Destruction, HC 898, London, The Stationery Office.

BOURKE, G., WORTHY, B. AND HAZELL, R. (2012) Making Freedom of Information Requests: A Guide for Academic Researchers, UCL Constitution Unit.

CFOI (2015) Campaign for Freedom of Information. Accessed at https://www.cfoi.org.uk/ EUROPEAN UNION (2013). A vision for public services

ec.europa.eu/information_society/newsroom/cf/dae/document.cfm.

FLINN, A. AND JONES, H. eds. (2009) Freedom of Information: Open Access, Empty Archives? Routledge.

GUARDIAN (2004). 'Leader' 15 July 2004.

http://www.theguardian.com/politics/2004/jul/15/butler.iraq1

GUARDIAN (2015). 'Repercussions of the release of Prince Charles's 'black spider memo' letters' 29 March 2015. http://www.theguardian.com/uk-

news/2015/mar/29/repercussions-release-of-prince-charles-black-spider-memo-letters GURSTEIN'S COMMUNITY INFORMATICS (2010). Open Data: Empowering the Empowered or Effective Data Use for Everyone? https://gurstein.wordpress.com/2010/09/02/open-dataempowering-the-empowered-or-effective-data-use-for-everyone/ 
HALONEN, A. (2012) Being Open about Data: Analysis of the UK open data policies and applicability of open data, Finnish Institute in London. http://www.finnishinstitute.org.uk/images/stories/pdf2012/being\%20open\%20about\%20data.pdf HAZELL, R. AND WORTHY, B. (2009) Impact of FOl on central government, UCL Constitution Unit.

HILLSBOROUGH INDEPENDENT PANEL (2012) Report.

http://hillsborough.independent.gov.uk/

MCDONAGH, M. (2006) Freedom of Information Law Dublin.

OPEN DEMOCRACY (2010). 'Blog, Blair's hostility to FOI'.

https://www.opendemocracy.net/ourkingdom/maurice-frankel/roots-of-blairs-hostility-tofreedom-of-information

ORDNANCE SURVEY OPEN DATA (2010), 'Ordnance Survey offers free data access'. Accessed at http://news.bbc.co.uk/1/hi/technology/8597779.stm

ROSENBAUM, M. (2012). 'Ireland reviews FOI fee which cut request level in half' Accessed at http://www.bbc.co.uk/news/uk-politics-18282530

SHEPHERD, E., FLINN, A. AND STEVENSON, A. (2009) 'The impact of freedom of information on records management and record use in local government: a literature review' Journal of the Society of Archivists 30: 2: pp. 227-248.

SHEPHERD, E., FLINN, A. AND STEVENSON, A. (2010) ‘nformation governance, records management and freedom of information: a study of local government authorities in England' Government Information Quarterly 27: 4: pp. 337-345. Published online 13/08/2010. DOI 10.1016/j.giq.2010.02.008 
SHEPHERD, E., FLINN, A AND STEVENSON, A. (2011a) 'Freedom of Information and records management in local government: help or hindrance?' Information Polity: the International Journal of Governance and Democracy in the Information Age 16: 2: pp. 111-121.

SHEPHERD, E., FLINN, A AND STEVENSON, A. (2011b) 'Records Management in English Local Government: the effect of freedom of information' Records Management Journal 21: 2: pp. 122 - 134. Dol http://dx.doi.org/10.1108/09565691111152053 STOLEN GENERATIONS (2015). Testimonieshttp://stolengenerationstestimonies.com/ UK CABINET OFFICE (2012) Open Data White Paper: Unleashing the Potential, Cm 8353. UK CABINET OFFICE (2013) Open Government Partnership UK National Action Plan 2013 to 2015. https://www.gov.uk/government/consultations/open-government-partnership-uknational-action-plan-2013/open-government-partnership-uk-national-action-plan-2013-to$\underline{2015}$ UK GOVERNMENT OPEN DATA (2013) Open Data Principles. https://www.gov.uk/servicemanual/technology/open-data.html UK, INFORMATION COMMISSIONER'S OFFICE (2012a) Ministerial veto on disclosure of parts of the minutes of Cabinet meetings in March 2003 Information Commissioner's Report to Parliament. HC 547. London, The Stationery Office.

UK, INFORMATION COMMISSIONER'S OFFICE (2012b) Anonymisation Managing Data Protection Risk Code of Practice.

http://www.ico.org.uk/for organisations/data protection/topic guides/anonymisation UK, INFORMATION COMMISSIONER'S OFFICE (2015a) ‘How to access information from a public body'. https://ico.org.uk/for-the-public/official-information/ 
UK, INFORMATION COMMISSIONER'S OFFICE (2015b) 'What happens when someone complains?' https://ico.org.uk/for-organisations/guide-to-freedom-ofinformation/complaints/

UK, LORD CHANCELLOR (2012) Government Response to the Justice Committee's Report: Post-legislative scrutiny of the Freedom of Information Act 2000, Cm 8505.

UK, MINISTRY OF JUSTICE AND THE NATIONAL ARCHIVES (2009) Lord Chancellor's Code of Practice on the Management of Records under s 46 of the FOI Act 2000.

http://www.justice.gov.uk/downloads/information-access-rights/foi/foi-section-46-code-ofpractice.pdf

UK, MINISTRY OF JUSTICE (2013). Secretary of State's Code of Practice (datasets) on the discharge of public authorities' functions under Part 1 of the Freedom of Information Act. Issued under Section 45 of the Freedom of Information Act.

https://www.gov.uk/government/publications/secretary-of-states-code-of-practicedatasets-on-the-discharge-of-public-authorities-functions-under-part-1-of-the-freedom-ofinformation-act

UK, THE NATIONAL ARCHIVES AND INFORMATION COMMISSIONER'S OFFICE, Memorandum of Understanding. (2012) <http://www.nationalarchives.gov.uk/documents/informationmanagement/mou-as-signed-18-july-2012.pdf>.

UK TRANSPARENCY BOARD (2010), Blog. http://data.gov.uk/blog/new-public-sector$\underline{\text { transparency-board }}$

WORTHY, B. (2010) 'More Open But not More Trusted? The Effect of the Freedom of Information Act 2000 on the United Kingdom Central Government' Governance 23 (4), pp. 561-582. 
WORTHY, B., AMOS, J., HAZELL, R. AND BOURKE, G. (2011) Town Hall Transparency? The Impact of the Freedom of Information Act on English Local Government, UCL Constitution

Unit.

\footnotetext{
${ }^{1}$ A version of this paper was first given at Fifth Conference on Archival Information Databases, Different Views of Online Archives: Digitization, Memory and Access, Rio de Janiero, Brazil in June 2013. I am grateful to my colleagues at UCL DIS, especially Dr Andrew Flinn, for contributions to this paper and to research in the field. ${ }^{2}$ Details are published on the website: http://www.ucl.ac.uk/dis/icarus/research-areas/foi-impact

${ }^{3}$ This section draws on a literature review prepared by Camille Anciaux-Duclert, visiting doctoral student at UCL in 2013, unpublished.
} 